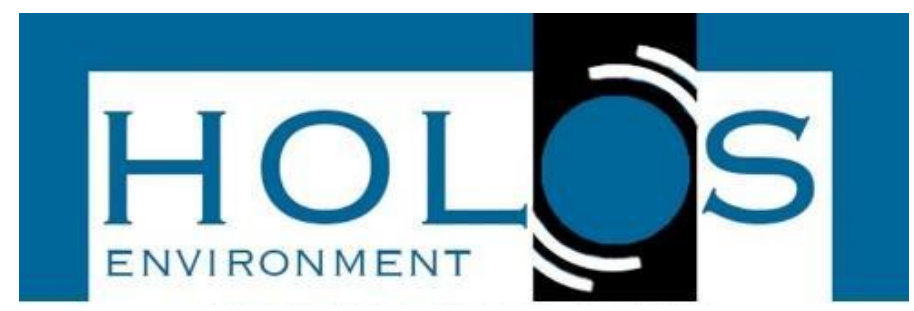

\title{
VULNERABILIDADE AMBIENTAL EM ÁREAS DE CAATINGAS NA UNIDADE DE CONSERVAÇAO PARNA DO CATIMBAU, PERNAMBUCO, SEMIÁRIDO BRASILEIRO
}

\author{
ENVIRONMENTAL VULNERABILITY IN CAATINGAS AREAS \\ IN THE CONSERVATION UNIT PARNA OF CATIMBAU, PERNAMBUCO, \\ BRAZILIAN SEMIARID
}

\author{
Ana Célia Saraiva de Moura Garcia ${ }^{1}$; Luana Cardoso de Andrade ${ }^{1}$; Adiel Felipe da \\ Silva Cruz ${ }^{1}$; Albert Einstein Spíndola Saraiva de Moura2; Patricio Rinaldo dos Santos ${ }^{1}$
}

Artigo recebido em: 08/06/2020 e aceito para publicação em: 26/08/2020.

DOI: http:/dx.doi.org/10.14295/holos.v20i4.12402

Resumo: O Parque Nacional do Catimbau é uma unidade de conservação integral muito importante na conservação da biodiversidade do bioma Caatinga. Estando situado na região semiárida de Pernambuco, na zona de transição entre o agreste e sertão, o parque comporta excessiva beleza de caatingas, monumentos esculpidos pela ação erosiva dos ventos em rocha arenítica e diversos sítios arqueológicos. Sabendo-se que - Parna do Catimbau constitui áreas de prioridade alta de conservação devido à susceptibilidade a desertificação, essa pesquisa teve como foco avaliar a vulnerabilidade das caatingas presentes nesta unidade de conservação. A metodologia utilizada contou com a aplicação do índice de vegetação ajustado ao solo (IVAS), sensoriamento remoto termal e visita em campo que permitiu a análise da espacialização das imagens orbitais, dos satélites Landsat 5 e 8 nos anos de 1995, 2006 e 2016. Os resultados mostraram aumento térmico nas áreas de caatingas e impactos ambientais ocasionados pela antropização de suas áreas. $\mathrm{A}$ antropização das caatingas no interior do Parna do Catimbau fere a Lei 9.985/00, que institui o Sistema Nacional de Unidades de Conservação (SNUC) e define as atribuições de uma unidade de conservação de uso integral. Sendo necessário para essa UC o alinhamento de sua gestão com o SNUC e a implantação de espaços de aprendizagem para disseminação da educação ambiental à população dos municípios que a integram.

Palavras-chave: Gestão ambiental. Educação ambiental. Sustentabilidade. Temperatura superficial.

Abstract: The Catimbau National Park is a very important integral conservation unit in the conservation of the biodiversity of the Caatinga biome. Located in the semi-arid region of Pernambuco, in the transition zone between the agreste and the sertão, the park contains excessive beauty of caatingas, monuments sculpted by erosive action of winds on sandstone and various archaeological sites. Knowing that Parna do Catimbau is a high priority conservation area due to the susceptibility to desertification, this research focused on assessing the vulnerability of the caatingas present in this conservation unit. The methodology used included the application of the soil-adjusted vegetation index (SAVI), thermal remote sensing and field visits that allowed the analysis of the spatialization of the orbital images, of the Landsat 5 and 8 satellites in the years 1995, 2006 and 2016. The results showed thermal increase in the areas of caatingas and environmental impacts caused by the anthropization of their areas. The anthropization of caatingas in the interior of Parna do Catimbau violates Law 9,985/00, which establishes the National System of Conservation Units (SNUC) and defines the attributions of a conservation unit for full use. It is necessary for this UC to align its management with the SNUC and to implement learning spaces for the dissemination of environmental education to the population of the municipalities that integrate it.

\footnotetext{
1 Universidade Federal do Vale do São Francisco (UNIVASF), Petrolina, PE. E-mails: anaclia1@gmail.com,

luanacardosodeandrade@gmail.com, felipe.adiel@gmail.com, patricioibimirim@hotmail.com

2 Instituto Federal de Educação, Ciência e Tecnologia de Pernambuco (IFPE), Recife, PE. E-mail: aessmoura@yahoo.com.br
} 
Keywords: Environmental management. Environmental education. Sustainability. Surface temperature.

\section{INTRODUÇÃO}

O Sistema Nacional de Unidades de Conservação (SNUC) define a Unidade de Conservação (UC) como "o espaço territorial legalmente definido e seus recursos ambientais, dotado de atributos naturais relevantes, instituído pelo Poder Público com objetivos de conservação e limites definidos, sob regime especial de administração ao qual se aplicam garantias adequadas de proteção" (BRASIL, 2000).

$\mathrm{Na}$ região semiárida do nordeste brasileiro as Unidades de Conservação (UCs) constituem grandes aliadas na proteção da biodiversidade do bioma caatinga, e, contudo, no enfrentamento e barramento de áreas susceptíveis à degradação (PERNAMBUCO, 2011).

As caatingas, na visão de Araújo Filho (2011) são formações vegetais xerófilas, lenhosas, decíduas, com muitas espécies espinhosas, compreendendo um estrato arbóreo esparso, outro arbóreo-arbustivo e/ou arbustivo, e um herbáceo estacional, conforme o período das chuvas.

Essa vegetação assume aspectos diferenciados de acordo com as variações climáticas ambientais, conforme Drumont et al., (2012) a Caatinga é definida como "mata branca", nome decorre da paisagem esbranquiçada apresentada pela vegetação durante o período seco, aonde a maioria das plantas perde as folhas e os troncos tornam-se esbranquiçados e secos.

É um bioma cuja existência limita-se no território do semiárido brasileiro, portanto, exclusivo patrimônio biológico do Brasil, o que significa que seus ecossistemas não são encontrados em nenhum outro lugar do globo terrestre, no entanto ainda é negligenciado (ANDRADE, 1981; VELLOSO et al., 2002; FREIRE, 2018).

$\mathrm{Na}$ região semiárida brasileira, não existe uma Caatinga, mas diversas formas criadas pela interação de seus seres vivos com o conjunto edafoclimático local, pois este bioma é formado por várias fitofisionomias (PRADO, 2003; DRUMONT et al., 2012).

As Caatingas no nordeste do Brasil ocupam uma área de cerca de $850.000 \mathrm{~km}^{2}$, cerca de $10 \%$ do território nacional, englobando de forma contínua parte dos estados do Maranhão, Piauí, Ceará, Rio Grande do Norte, Paraíba, Pernambuco, Alagoas, Sergipe, 
Bahia (região Nordeste do Brasil) e parte do norte de Minas Gerais (região Sudeste do Brasil), seguindo o rio São Francisco (PRADO, 2003).

Devido à grande diversidade, o bioma da Caatinga foi segmentado em oito ecorregiões e são: Complexo de Campo Maior, Depressão Sertaneja Meridional, Complexo Ibiapaba - Araripe, Dunas do São Francisco, Depressão Sertaneja Setentrional, Complexo da Chapada Diamantina, Planalto da Borborema e Raso da Catarina (VELLOSO, 2002).

De acordo com Velloso (2002), dentre as ecorregiões mais degradadas pela ação antrópica estão as duas ecorregiões da Depressão Sertaneja: a Depressão Sertaneja Setentrional e a Depressão Sertaneja Meridional. Além disso, elas possuem poucas áreas protegidas, em termos de número, área total ou categoria de proteção, mas ainda possuem áreas razoavelmente extensas com possibilidade de recuperação.

A bacia do rio São Francisco médio e seus tributários estão atualmente em um limite climático de exorreísmo, e mudanças permanente na precipitação irá resultar em condições endorréicas, como por exemplo aumento subsequentes de salinidade (PRADO, 2003).A preservação da biodiversidade da caatinga, por meio das UCs constitui parâmetro importante para a gestão ambiental, no sentido de prevenção nas áreas susceptíveis à desertificação, assim como na restauração e reabilitação das áreas degradadas e desertificadas (GARCIA, 2018).

Na região Nordeste do Brasil, algumas áreas de caatingas apresentam problemas de desertificação, como: Gilbués, PI; Irauçuba, CE; Seridó, RN; e Cabrobó, PE devido a degradação antrópica desse bioma (KILL et al., 2007).

Por sua vulnerabilidade natural as caatingas protegem de forma passiva o solo da erosão, tornando-o vulnerável a degradação. As precipitações, nas regiões de caatingas degradadas ocasionam forte poder erosivo, diminui a capacidade de retenção hídrica e reduz a biomassa vegetal (OLIVEIRA et al., 1992; KILL et al., 2007).

Assim, a cobertura vegetal torna-se cada vez mais rala, pobre em biodiversidade, e consequentemente o solo passa a receber diretamente à radiação solar, que acelera a erosão, aumentando a aridez (FREIRE; PACHÊCO, 2011).

Por outro lado, a vegetação do Bioma Caatinga apresenta modificações que permitem sua sobrevivência nos longos períodos de estiagem, características como a queda das folhas na estação seca, a presença de caules e raízes suculentas que armazenam água e nutrientes, o ciclo de vida curto e a dormência das sementes (KILL et al.,2007). 
As unidades de conservação têm importante papel na sustentabilidade dos ecossistemas locais, como ressalta Brown (1996), as florestas além de armazenar grandes quantidades de carbono no solo e na vegetação, trocam $\mathrm{CO}_{2}$ com a atmosfera, e têm a capacidade de mitigar os impactos das mudanças climáticas.

Conforme a Lei n. 9.985, de julho de 2000, o Sistema Nacional de Unidades de Conservação da Natureza (SNUC) legítima dois tipos de unidades de conservação: o uso integral e o uso sustentável, conforme o Quadro 1.

Figura 1 - Tipos de unidades de conservação de proteção integral e unidades de uso sustentável

\begin{tabular}{|c|c|}
\hline UNIDADES DE PROTEÇÃO INTEGRAL & UNIDADES DE USO SUSTENTÁVEL \\
\hline Estação Ecológica (Esec) & Área de Proteção Ambiental (APA) \\
\hline Reserva Biológica (Rebio) & $\begin{array}{l}\text { Área de Relevante Interesse Ecológico } \\
\text { (Arie) }\end{array}$ \\
\hline Parque Nacional (Parna) & Floresta Nacional (Flona) \\
\hline Monumento Natural (MN) & Reserva Extrativista (Resex) \\
\hline Refúgio de Vida Silvestre (Revis) & Reserva de Fauna (Refau) \\
\hline & $\begin{array}{l}\text { Reserva de Desenvolvimento Sustentável } \\
\text { (RDS) }\end{array}$ \\
\hline & $\begin{array}{l}\text { Reserva Particular do Patrimônio Natural } \\
\text { (RPPN) }\end{array}$ \\
\hline
\end{tabular}

Fonte: Brasil (2000); editado pelos autores.

Conforme a Figura 1 as unidades de proteção integral contam com 5 unidades e as de uso sustentável com 12 unidades. As unidades de uso integral são aquelas com a permissão do uso indireto dos recursos naturais, como o turismo ecológico e pesquisas científicas. Já as unidades de uso sustentável, permitem a conservação ambiental com o uso sustentável dos recursos naturais, admitindo a presença humana em seu interior (BRASIL, 2000).

De acordo com o Cadastro Nacional de Unidades de Conservação-CNUC (2019), aproximadamente 9\% do Bioma Caatinga se encontra distribuído em 209 unidades de conservação, totalizando apenas $73.480,60 \mathrm{Km}^{2}$ áreas protegidas, destes $2 \%$ em unidades de proteção integral (como Parques, Reservas Biológicas e Estações Ecológicas), e 7\% em unidades de uso sustentável.

No entanto, mesmo em áreas de proteção integral a Caatinga está em risco, já que pesquisas realizadas por Freire et al. (2015), apontam a vulnerabilidade do Bioma Caatinga das UCs do semiárido brasileiro.

Nesse sentido, a gestão ambiental das unidades de conservação situadas na região semiárida no Nordeste do Brasil, tem fundamental importância na preservação e conservação dos recursos naturais, tendo em vista a vulnerabilidade da região nordeste 
aos impactos das anomalias e variabilidade climática (MARENGO, 2007; MARENGO, 2016).

O sensoriamento remoto contribui na gestão ambiental das UCs, pois trata-se de uma tecnologia que possibilita a aquisição de imagens e outros tipos de dados, oriundos da superfície terrestre, através da captação e do registro da energia refletida ou emitida dos objetos terrestres (JESEN, 2009; NOVO, 2010; FLOREZANO, 2013), capaz de identificar possíveis mudanças ambientais ocorridas na paisagem.

Nesse contexto, é proposto esse trabalho focado na vulnerabilidade das caatingas de uma Unidade de Proteção Ambiental Integral com uso conjugado de técnicas do sensoriamento remoto e pesquisa de campo.

De acordo com Negash (2016) há legitimação no uso do sensoriamento remoto na detecção, avaliação e monitoramento da degradação ambiental, pois as radiações eletromagnéticas refletidas, transmitidas, absorvidas, apresentam valores diferenciados nos seus comprimentos de ondas.

Os índices de vegetação são definidos como medidas radiométricas adimensionais, as quais indicam a abundância relativa e a atividade fotossintética. Os índices relacionam os valores refletidos da banda do infravermelho próximo do espectro, que permite detectar na paisagem a água, o solo e a vegetação (GLENN et al., 2008; JESSEM, 2009).

Com a aplicação dos índices de vegetação é possível analisar as superfícies vegetadas e degradadas, decorrentes de impactos antrópicos ou naturais (FEITOSA et al., 2004), devido à alta correlação da fitomassa verde com o grau de cobertura do solo por vegetação (KUNDU; DUTTA , 2011; BEZERRA et al., 2014).

Em áreas de caatingas o uso do índice de vegetação ajustado para os efeitos do solo (IVAS) é o mais indicado ameniza os efeitos do "background" do solo. É calculado por meio da relação das bandas do infravermelho próximo e do vermelho (HUETE, 1988).

Existe uma correlação entre os índices de vegetação com a temperatura superficial (WENG; SCHUBRING, 2004), isso porque a densidade da vegetação é um fator influente de controle de medidas da temperatura superficial., assim é possível a averiguar a qualidade ambiental (OLIVEIRA ; ROSA, 2013).

Esse trabalho teve como objetivo analisar a vulnerabilidade das caatingas na Unidade de Proteção Ambiental Integral Parna do Catimbau, Pernambuco, a partir da espacialização dos Índices de vegetação ajustado ao solo (IVAS) e variação da temperatura superficial (Ts). 


\section{MATERIAL E MÉTODOS}

\subsection{Localização da área de estudo}

O Parque Nacional do Catimbau está localizado no submédio da bacia do rio São Francisco, localizado na bacia do rio Moxotó (Figura 1). É uma das unidades de conservação do bioma Caatinga, inserida no Estado de Pernambuco. Possui área total de 62.294 hectares, sua paisagem natural, é marcada pela exuberante geomorfologia de seu relevo (FREIRE et al., 2015).

Figura 2 - Localização do Parna do Catimbau

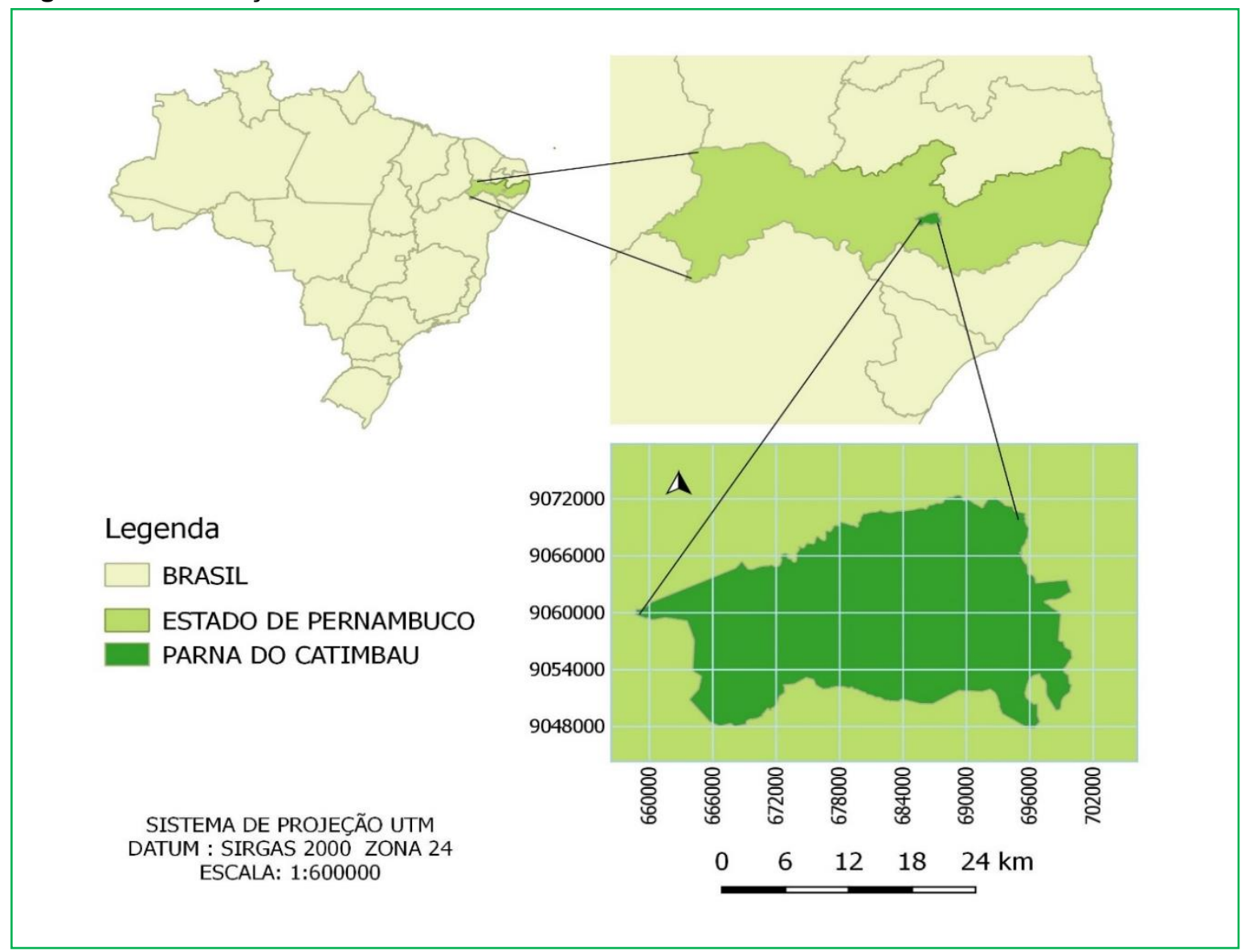

Fonte: Elaborado pelos autores (2020).

A metodologia do projeto incluiu etapas teóricas e práticas, foi realizado inicialmente o levantamento bibliográfico acerca do tema utilizando as plataformas de pesquisas como: Scielo, Periódicos CAPES, Google Acadêmico, BDTD - Biblioteca Digital Brasileira de Dissertações e Teses, dentre outros. 
$\mathrm{Na}$ parte prática foram realizadas atividades de geoprocessamento com o uso do Sistema de Processamento de Informações Georreferenciadas- SPRING (CÂMARA et al., 1996), na versão 5.2.6. E, foi utilizado também o QGis na versão 2.18 para a elaboração dos mapas.

Utilizou-se um banco de dados georreferenciado com imagens de satélites LANDSAT 5 TM e LANDSAT 8 OLI com órbita/pontos 215/66 em datas distintas de influência de eventos ENOS moderado (1995), fraco (2006) e forte (2019), adquiridas gratuitamente no catálogo de imagens da instituição de Pesquisa Geológica dos Estados Unidos - USGS (2019).

Todos os cálculos (Figura 3) foram realizados na Programação em Legal do SPRING 5.5.

Figura 3 - Quadro de Procedimentos físicos utilizados no estudo

\begin{tabular}{|c|c|c|}
\hline Procedimentos físicos & Fórmula & Autor(es) \\
\hline $\begin{array}{l}\text { Índice de Vegetação Ajustado } \\
\text { ao Solo - IVAS }\end{array}$ & $I V A S=\frac{(I V P-V)}{(I V P+V+L)} *(1+L)$ & $\begin{array}{l}\text { HUETE (1988); PONZONI E } \\
\text { SHIMABUKURO (2007) }\end{array}$ \\
\hline $\begin{array}{l}\text { Calibração radiométrica das } \\
\text { imagens Landsat } 5\end{array}$ & $L \lambda i=a i+\frac{b i-a i}{255} N D$ & $\begin{array}{l}\text { MARKHAM E BAKER (1987); } \\
\text { CHANDER et al (2009) }\end{array}$ \\
\hline $\begin{array}{l}\text { Cálculo da reflectância } \\
\text { monocromática }\end{array}$ & $\rho \lambda=\frac{\pi \cdot L \lambda}{E \lambda \cdot \cos (z) \cdot d r}$ & MARKHAM E BAKER, 1987 \\
\hline $\begin{array}{l}\text { Conversão para a radiância do } \\
\text { topo da atmosfera (TOA) para } \\
\text { as imagens da banda } 10 \text { do } \\
\text { sensor Thermal Infrared } \\
\text { Sensor (TIRS) LANDSAT-8 }\end{array}$ & $\rho \lambda=M \rho Q c a l+A \rho$ & USGS (2019): \\
\hline $\begin{array}{l}\text { Índice de Vegetação } \\
\text { Normalizada - IVDN }\end{array}$ & $I V D N=\frac{(I V P-V)}{(I V P+V)}$ & $\begin{array}{l}\text { HUETE (1988); PONZONI e } \\
\text { SHIMABUKURO (2007) }\end{array}$ \\
\hline $\begin{array}{l}\text { Índice de Vegetação ajustada } \\
\text { ao solo - IVAS }\end{array}$ & $I V A S=\frac{(I V P-V)}{(I V P+V+L)} *(1+L)$ & $\begin{array}{c}\text { HUETE, 1988; KARNIELI et } \\
\text { al., } 2001\end{array}$ \\
\hline Índice de Área Folhear (IAF) & $I A F=\left(\frac{\frac{0,69-I V A S}{0,59}}{0,91}\right)$ & ALLEN et al., 2002. \\
\hline $\begin{array}{l}\text { Cálculo emissividade de cada } \\
\text { pixel no domínio da banda } \\
\text { termal }\end{array}$ & $\varepsilon N B=0,97+0,00331 \mathrm{IAF}$ & ALLEN et al., 2002 \\
\hline A emissividade da superfície & $(\varepsilon 0)=0,95+0,01 \mathrm{IAF}$ & TASUMI, 2003 \\
\hline Temperatura superficial & $T s=\frac{k 2}{\operatorname{In}\left(\frac{\varepsilon N B K 1}{L \lambda 6}+1\right)}$ & BASTIAANSSEN et al., 2000 \\
\hline
\end{tabular}

Fonte: Elaborado pelos autores (2020). 


\subsection{Dados pluviométricos}

Os dados pluviométricos referentes às datas em estudo foram obtidos juntamente à Agência Pernambucana de Águas e Clima (APAC, 2019), foram adquiridos dados sobre a temperatura do ar na Plataforma de coleta de dados - PDC, n 32289/Estação Ibimirim e Estacão 82890-Arcoverde do BDMEP. Os dados de ocorrência de eventos ENOS (EI Niño moderado, fraco e forte) para o período de estudo-órbita 215 foram analisados segundo os dados apresentados por Null (2017) e INPE (2016).

\subsection{Trabalho de campo}

A atividade de campo teve como objetivo conhecer áreas de caatingas. Essa atividade foi realizada no município de Buíque, área de acesso ao Parna do Catimbau, onde se pôde fazer o registro fotográfico das paisagens e georreferenciar áreas de caatingas (arbustiva, arbórea, herbácea) para apoiar a análise e interpretação dos dados.

\section{RESULTADOS E DISCUSSÃO}

A vulnerabilidade ambiental das caatingas na Unidade de Conservação Parna do Catimbau pôde ser constatada a partir da análise temporal das mudanças ocorridas na espacialização da temperatura superficial, dos índices de vegetação ajustado ao solo e observação no campo.

A Tabela 1 mostra resultados dos valores estatísticos: mínimo, máximo da temperatura superficial da órbitas/ponto 215/66 para as datas 20 de setembro de 1995, 18 de setembro de 2006, e 20 de setembro de 2016.

Tabela 1 - Representação dos valores estatístico mínimo e máximo da Ts Parna do Catimbau

\begin{tabular}{ccc}
\hline Ano & Mínimo $\left({ }^{\circ} \mathbf{C}\right)$ & Máximo $\left({ }^{\circ} \mathbf{C}\right)$ \\
\hline 1995 & 20,00 & 36,20 \\
2006 & 22,89 & 38,00 \\
2016 & 24,00 & 39.90
\end{tabular}

Fonte: Elaborado pelos autores (2020). 
De acordo com a Tabela 1, percebe-se aumento da temperatura superficial de modo crescente ao longo dos anos nas datas em estudo, aproximadamente $4^{\circ} \mathrm{C}$ de elevação da Ts máxima e mínima do ano de 1995 ao ano de 2016. São dados importantes, pois a continuidade da elevação da temperatura superficial nas áreas de caatingas poderá comprometer a sobrevivência de espécies endêmicas e impactar todo o ecossistema da região.

As variações das Ts podem ser vista na Figura 4 ( $A, B$ e $C$ ), assim as áreas de caatingas densas, preservadas apresentam temperaturas mais amenas e as áreas de caatingas degradadas e solos desnudos apresentam temperaturas mais altas, mesmo estando sob influências climáticas do El Niño moderado (ano 1995), fraco (ano de 2006) e forte (no ano 2016), conforme Null (2017).

Nota-se que ao longo dos anos, a cor azul escuro que representava a mancha de temperatura abaixo dos $20^{\circ} \mathrm{C}$ no ano de 1995 , torna-se azul claro para o intervalo de classe entre $21^{\circ} \mathrm{C}$ e $23^{\circ} \mathrm{C}$ no ano de 2006 , e no ano de 2016 a mancha passa a ser representada pela cor laranja no intervalo entre $24^{\circ} \mathrm{C}$ e $27^{\circ} \mathrm{C}$. Esse intervalo de classe compreende as áreas de caatingas arbustivas densas a arbóreas, em alguns trechos essas áreas correspondem às áreas mais elevadas do Parna do Catimbau.

As áreas de caatingas degradadas, como os solos expostos e caatinga herbácea esparsa correspondem ao intervalo de classe entre $24^{\circ} \mathrm{C}$ a $26^{\circ} \mathrm{C}$ (cor amarela) no ano de 1995. No ano de 2006 esta classe está representada no intervalo entre $30^{\circ} \mathrm{C}$ a $32^{\circ} \mathrm{C}$ (cor laranja), e em 2016 devido a influencia climática do El nino forte, o intervalo passou a ser representado pelo intervalo de $33^{\circ} \mathrm{C}$ a $35^{\circ} \mathrm{C}$ (cor vermelha). Em algumas áreas de formações rochosas desnudas com ausência de vegetação rupestre a Ts atingiu temperaturas acima que $39^{\circ} \mathrm{C}$.

No entanto os valores da temperatura superficial adquiridos pela Plataforma de coleta de dados - PDC, n 32289/Estação Ibimirim e Estacão 82890-Arcoverde do BDMEP referentes às datas de estudo, não foram iguais aos captados pelos sensores orbitais térmicos das bandas Landsat 5 e 8.

De acordo com Tomlinson et al.(2011), ainda não há respostas para as diferenças entre as Ts captadas por estações meteorológicas e pelos sensores orbitais. Autores como Oliveira e Galvíncios (2009), Lins (2017) também observaram essas diferenças entre os resultados das temperaturas coletadas por sensores orbitais térmicos e estações meteorológicas em suas pesquisas. 
Figura 4 - Espacialização da Ts nas imagens de 1995(A), 2006 (B) e 2016 (C) e do IVAS nas imagens de 1995(D), 20006 (E) e 2016 (F) no PARNA do Catimbau-PE

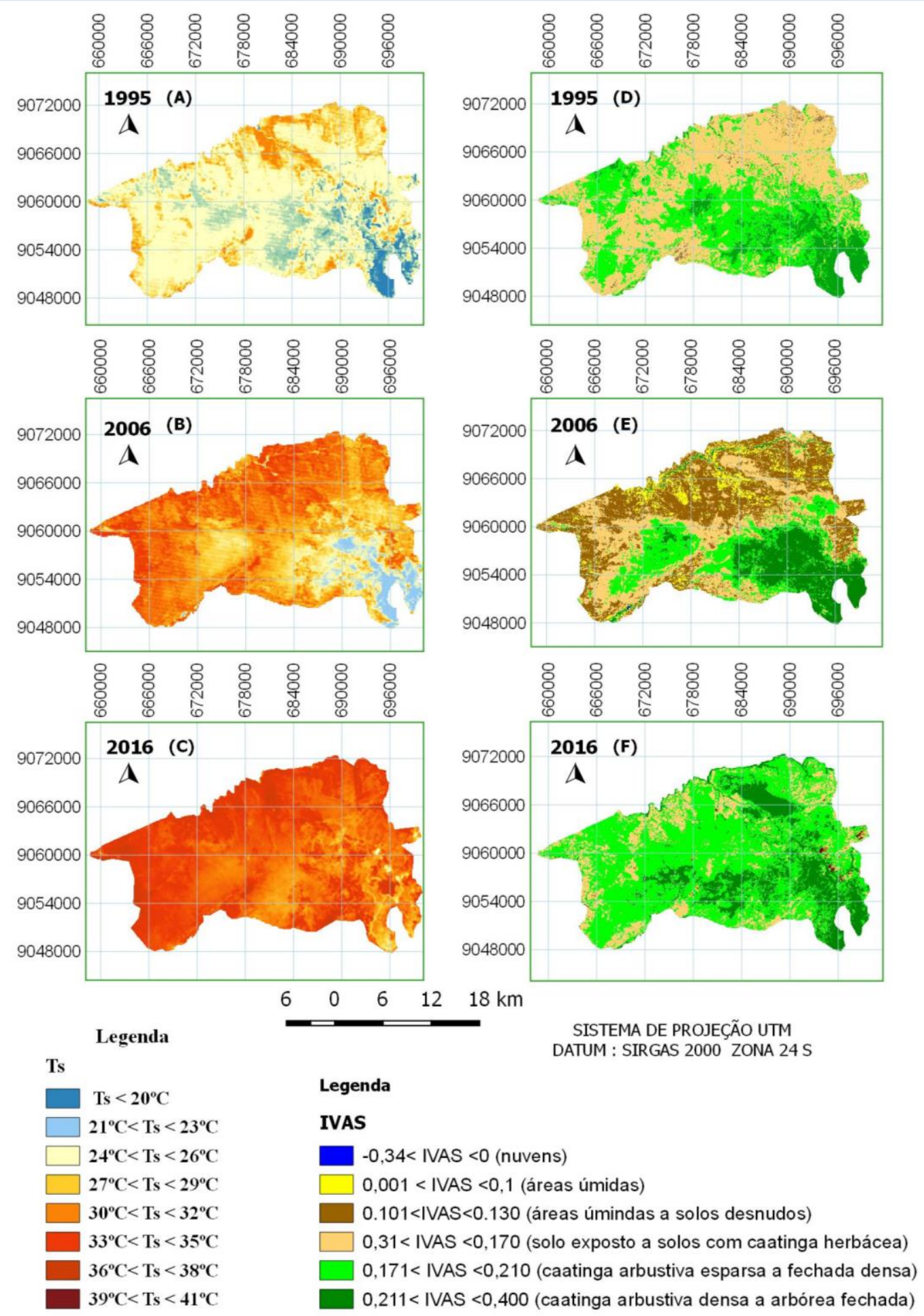

Fonte: Elaborado pelos autores (2020).

Relativo aos resultados da espacialização do IVAS é possível identificar áreas de caatingas visivelmente recuperadas desde o ano de 1995 ao ano de 2016 no Parna do Catimbau, representados na Figura 4 (D,E,F). Nota-se, sutil degradação em áreas cobertas por caatingas arbóreas e que foram substituídas pelas caatingas herbáceas e arbustivas. 
Com as medidas de classe pôde-se obter a representação em extensão de áreas em $\mathrm{km}^{2}$, assim o intervalo entre 0,131 a 0,170 (cor bege) representam na sua maior parte solos expostos degradados com vegetação herbácea esparsa. Essas áreas no ano de 1995 correspondiam a 315,26 km², no ano de 2006 essas áreas ocupavam 186,98 km² e em 2016 representavam $115,73 \mathrm{~km}^{2}$.

Os valores em extensão de áreas das caatingas arbustivas esparsas a caatingas fechadas no intervalo de 0,171 a 0,210, no ano de 1995 estimavam 222,10 km², no ano de 2006 correspondiam a 100,08 km² e em 2016 representavam 374,69 km², a Figura 5 (c) mostra paisagem da caatinga arbustiva, localizada no ponto $n^{\circ} 94$.

As áreas de caatingas arbustiva densa a arbórea fechada presentes no intervalo de 0,211 a 0,300 no ano de 1995 representavam 74,72 km², em 2006 essas áreas passaram para 100,21 km² e no ano de 2016 estimavam aproximadamente $128,47 \mathrm{~km}^{2}$. Contudo, a extensão de áreas de caatingas recuperadas e preservadas no ano de 2016 era para ser maior.

Figura 5 - Paisagem de áreas de caatingas no Parna do Catimbau: (a) Espacialização do IVAS em um trecho do Parna do Catimbau no ano de 2016. Registro fotográfico de áreas de caatingas no Sítio Chapadão, fotos tiradas no dia 25 de janeiro de 2018: (b) foto da caatinga arbustiva fechada localizada no P.091, (c) foto da paisagem dos paredões do Catimbau e (d) foto da vegetação rupestre nas rochas areníticas, aproximadamente a 100m do P.093

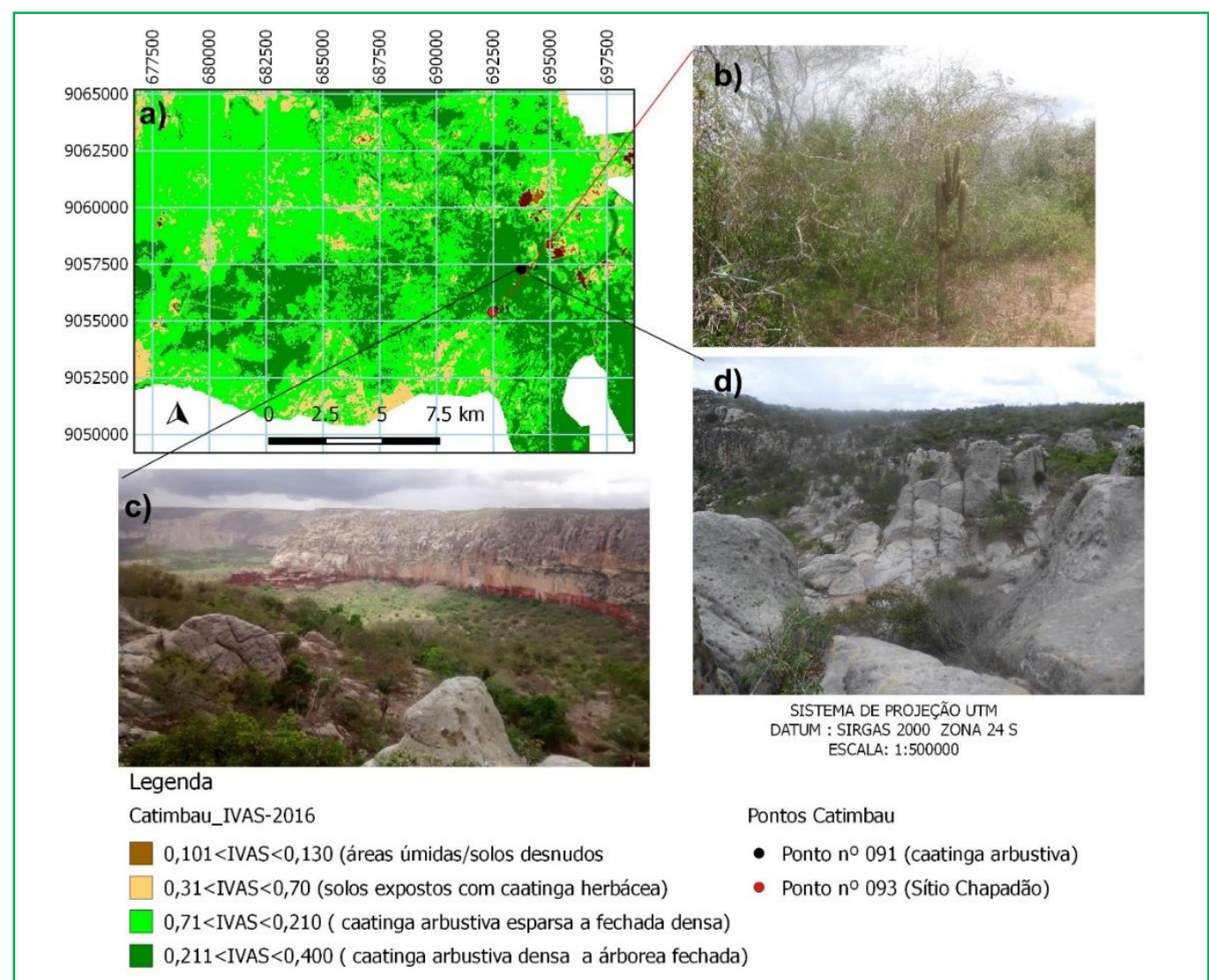

Fonte: Elaborado pelos autores (2020). 
A Figura 5 (c) mostra a paisagem no alto do sítio Chapadão, na formação arenítica dos paredões do catimbau, na imagem é possível perceber em algumas áreas dos paredões ausência de vegetações rupestres. Freire (2015), já relacionava os impactos das mudanças climáticas com a sustentabilidade da vegetação rupestre da caatinga, pois essa espécie endêmica depende da absorção hídrica dos arenitos, mesmo considerando a existência de elevações rochosas sem cobertura vegetal na composição da paisagem natural.

Não foram encontradas áreas correspondentes aos corpos hídricos, os trechos com áreas negativas $(-0,34)$ representadas pela cor azul foram imperceptíveis na composição da imagem, no entanto essas áreas representam sombra de algumas elevações rochosas e nuvens presentes nas imagens.

No que concerne às áreas degradadas, constatou-se no Parna do Catimbau áreas antropizadas no trecho de acesso ao chapadão. A Figura 6 mostra o registro fotografico dessas áreas, no dia 25 de janeiro de 2018, como: residências, criação de bovinos, plantação de agricultura de subsistência, queimadas e barreiro.

Figura 6 - Áreas antropizadas pela população residente no interior do Parna do Catimbau: (a) Criação de bovinos, (b) Plantação de milho e caju, (c) Residência e (d) Pequeno barreiro para dessedentação animal

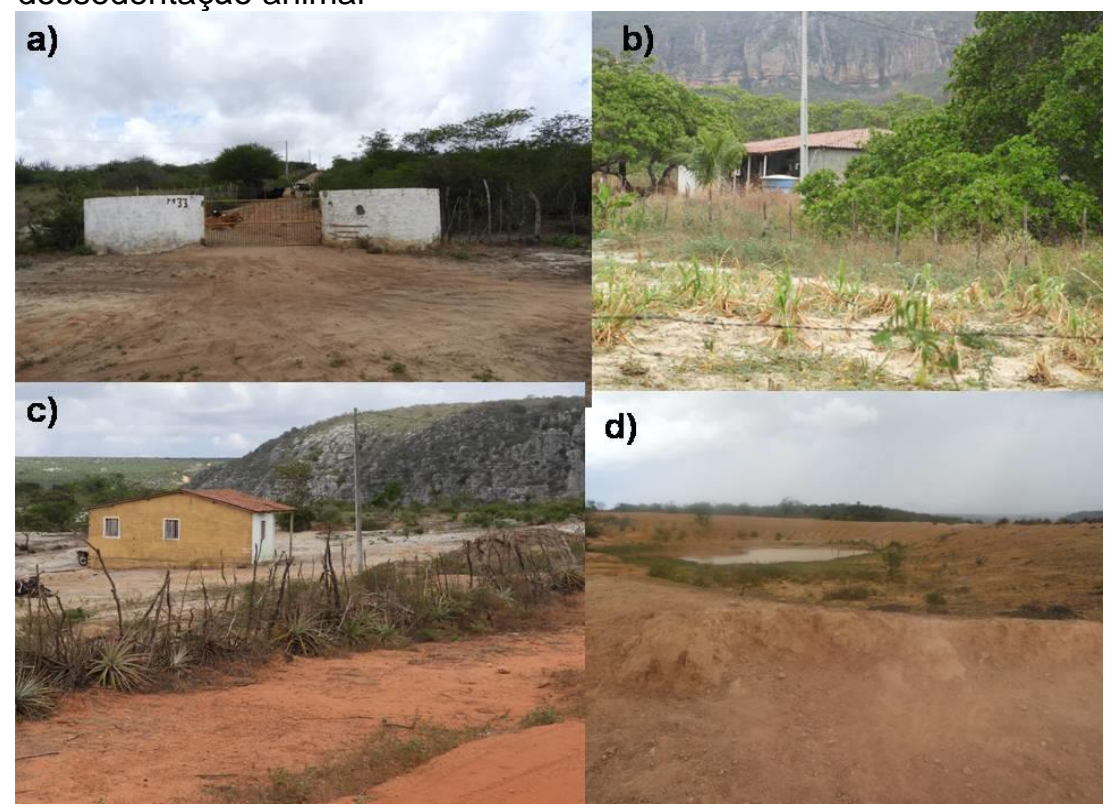

Fonte: Elaborado pelos autores (2020).

As atividades antropizadas contrariam a Lei $n .^{\circ} 9.985$, de 18 de julho de 2000 e o Decreto 4.340, de 22 de agosto de 2002. Mais precisamente, o Art. 11. da Lei n. ${ }^{\circ}$ 9.985, de 18 de julho de 2000 no seu inciso $\S 1$ 으 trata da desapropriação de áreas particulares, "O 
Parque Nacional é de posse e domínio público, sendo que as áreas particulares incluídas em seus limites serão desapropriadas, de acordo com o que dispõe a lei".

Contudo, essa situação mostra a fragilidade do gerenciamento dessa unidade de conservação, sendo necessário um replanejamento no plano de gestão do Parna do Catimbau alinhados com a SNUC (BRASIL, 2000). Contudo, que esse plano contemple uma gestão ambiental compartilhada com os municípios que a integram com a promoção de ações em educação ambiental interdisciplinar a médio e longo prazo.

\section{CONCLUSÕES}

A metodologia mostrou-se adequada na identificação da vulnerabilidade das caatingas na unidade de proteção integral Parna do Catimbau, partir do uso conjugado do índice de vegetação ajustado ao solo, sensoriamento termal e atividade de campo.

A área do Parna do Catimbau é bastante influenciada pelos impactos dos Eventos ENOS, no entanto, o aumento térmico da temperatura superficial $e$ as atividades antropizadas no interior do Parque acentuam a vulnerabilidade da degradação das caatingas, podendo vir a comprometer a sustentabilidade ecossistêmica da área.

As variações da temperatura superficial nas áreas de caatingas e os impactos nas espécies endêmicas devem ser estudados e monitorados, a antropização de suas áreas deve ser combatida, pois ferem a Lei n. 9.985, de julho de 2000 e evidencia a fragilidade no processo de gerenciamento no âmbito dessa UC.

Supostamente uma boa estratégia para maior proteção dessa UC, será um plano de gestão e educação ambiental integrado, com base em sistemas complexos. A criação de espaços de aprendizagem e disseminação da educação ambiental nos municípios de entorno da Unidade de conservação poderá fortalecer e favorecer o surgimento de uma gestão integrada do poder público federal, municipal, estadual e sociedade civil, e o reconhecimento das contribuições dos serviços ecossistêmicos do Parna do Catimbau para todo o submédio do rio São Francisco.

\section{AGRADECIMENTOS}

A Universidade Federal do Vale do São Francisco (UNIVASF) e ao Programa de PósGraduação em Educação Ambiental Interdisciplinar. À Fundação Joaquim Nabuco, pela oportunidade de ser selecionada e participar do Curso de Sensoriamento Remoto e 
Monitoramento Ambiental. Ao Prof. Dr. Neison Freire, pelos ensinamentos e discussões durante o Curso de Sensoriamento Remoto e Monitoramento Ambiental.

\section{REFERÊNCIAS}

ALLEN, R.; BASTIAANSSEN, W.; WATERS, R.; TASUMI, M.; TREZZA, R. Surface energy balance algorithms for land (SEBAL). Idaho implementation - Advanced training and users manual, v. 1.0, 2002.

ANDRADE, L. D. The caatingas dominium. Revista Brasileira de Botânica, São Paulo, v. 4, 1981.

APAC. Agência Pernambucana de Águas e Clima. Dados históricos- monitoramento pluviométrico. Disponível em: http://www.apac.pe.gov.br/metereorologia/monitoramento-pluvio.php. Acesso em: 22 set 2019.

ARAUJO FILHO, J. C. Relação solo e paisagem no Bioma Caatinga. In: SIMPÓSIO BRASILEIRO DE GEOGRAFIA FÍSICA APLICADA, 14., 2011, Dourados. [Anais...]" Dinâmicas socioambientais das inter-relações às interdependência". Dourados: UFGD, 2011.

BASTIAANSSEN, W.G.M. SEBAL - based sensible and latent heat fluxes in the irrigated Gediz Basin, Turkey. Journal of Hydrology, v. 229, p. 87-100, 2000. https://doi.org/10.1016/S0022-1694(99)00202$\underline{4}$

BRASIL. Lei no 9.985, de 18 de julho de 2000. Institui o Sistema Nacional de Unidades de Conservação - SNUC, Brasília: Diário oficial de 19/07/2000.

BEZERRA, J. M.; MOURA, G. B. D. A.; SILVA, B. B. D.; LOPES, P. M.; SILVA, Ê. F. D. F. Parâmetros biofísicos obtidos por sensoriamento remoto em região semiárida do estado do Rio Grande do Norte, Brasil. Revista Brasileira de Engenharia Agrícola e Ambiental, v. 18, n. 1, p. 73-84, 2014. https://doi.org/10.1590/S1415-43662014000100010

BROWN, S. Present and potential roles of forests in the global climate change debate. Unasylva, v. 185, pp. 3-9, 1996.

CADASTRO NACIONAL DE UNIDADE DE CONSERVAÇÃO DO MINISTÉRIO DO MEIO AMBIENTE CNUC/MMA. Disponível em: http://mapas,mma,gov,br/i3geo/datadownload,htm. Acesso em: 09 dez. 2019.

CÂMARA, G.; CARTAXO, R.; SOUZA, M.; FREITAS, U. M.; GARRIDO, J.; II, F. M. Spring: integrating remote sensing and gis by object-oriented data modelling. COMPUTERS \& GRAPHICS, v. 20, p. 395403, 1996.https://doi.org/10.1016/0097-8493(96)00008-8

CHANDER, G.; MARKHAN, B., L.; HELDER,D., L. Sumary of current radiometric calibration coefficients for Landsat MSS, TM, ETM+, and EO-1 ALI Sensors. ELSEVIER, Remote Sensing of Enviroment 113, 2009.https://doi.org/10.1016/j.rse.2009.01.007

DRUMOND, M. A.; SCHISTEK, A.; SEIFFARTH, J. A. Caatinga: um bioma exclusivamente brasileiro e o mais frágil. Revista do Instituto Humanitas Unisinos (IHU), v. 12, n. 389, abr. 2012. Disponível em: http://www.ihu.unisinos.brl. Acesso em: 01 set. 2019.

FEITOSA, J. R. P.; COSTA FILHO, JF da; SILVA, BB. Avaliação de índices de vegetação em área irrigada do sub-médio São Francisco, Petrolina-PE, a partir de imagens do satélite LANDSAT 5-TM. In: CONGRESSO BRASILEIRO DE METEOROLOGIA. [Anais...], 2004.

FLORENZANO, T.G. Iniciação em sensoriamento remoto. São Paulo: Oficina de Textos, 2013. 
FREIRE, N.C.F.; PACHÊCO, A.P. Desertificação: análise e mapeamento. Recife: Editora Universitária UFPE, 2011.

FREIRE, N. C. F.; MOURA, D.C.; SILVA, J.B.; PACHECO, A.P. Mapeamento e Análise EspectroTemporal das Unidades de Conservação de Proteção Integral da Administração Federal no Bioma Caatinga. Recife: Fundação Joaquim Nabuco, Editora Massangana, 2015.

FREIRE, N. C. F.; MOURA, D.C.; SILVA, J.B.; PACHECO, A.P. Atlas das caatingas- o único bioma exclusivamente brasileiro. Recife: Fundação Joaquim Nabuco, Editora Massangana, 2018.

GARCIA, A. C. S. M. Estudo espaço temporal de áreas susceptíveis à desertificação do semiárido brasileiro. Dissertação (Mestrado) - IFPE- Recife, PE, 2018.

GLENN, E. P.; Huete, A. R.; Nagler, P. L.; Nelson, S. G. Relationship between remotely sensed vegetation indices, canopy attributes and plant physiological processes: what vegetation indices can and cannot tell us about the landscape. Sensors, v. 8, n.4, p. 2136-2160, 2008.

https://doi.org/10.3390/s8042136

HUETE, A.R. A soil-ajusted vegetation index (SAVI), remote sensing of environment, 1988. https://doi.org/10.1016/0034-4257(88)90106-X

INPE-Instituto Nacional de Pesquisas Espaciais - Centro de Previsão de Tempo e Estudos Climáticos. INPE-CPTEC. ENOS. Cachoeira Paulista: CPTEC-INPE, 2016. Disponível em:

http://enos.cptec.inpe.br/\#. Acesso em: 07 set. 2019.

JENSEN, J. Sensoriamento remoto do ambiente: uma perspectiva em recursos terrestres. São José dos Campos, SP: Parêntese, 2009.

KARNIELI,A.;KAUFMAN,Y.J.;REMER,L.;WALD,A.AFRI-Aerosol free vegetation index. Remote Sensing of Environment, v. 77, n. 1, p. 10-21, 2001. https://doi.org/10.1016/S0034-4257(01)00190-0.

KILL, L. H. P.; DRUMOND, M.; LIMA, P.; de ALBUQUERQUE, S. G.; de OLIVEIRA, V. R. (2007). Preservação e uso da caatinga. Área de Informação da Sede-Col Criar Plantar ABC 500P/500R Saber (INFOTECA-E), 2007.

KUNDU, A.; DUTTA, D. Monitoring desertification risk through climate change and human interference using remote sensing and GIS techniques. International journal of geomatics and GeoSciences, v. 2, n. 1, p. 21, 2011

LINS, F.A.C.; SANTOS ARAÚJO,D.C.; SILVA,J.L.B; LOPES,P.M.O.; OLIVEIRA,J.D.A. Estimativa de parâmetros biofísicos e evapotranspiração real no semiárido Pernambucano utilizando sensoriamento remoto. IRRIGA, v. 1, n. 1, p. 64-75, 2017.

https://doi.org/10.15809/irriga.2017v1n1p64-75

MARENGO, J.A.; CUNHA, A. P.; ALVES, Lincoln M. A seca de 2012-15 no semiárido do Nordeste do Brasil no contexto histórico. Climanálise, v. 3, p. 1-6, 2016.

MARENGO, J.A. Mudanças climáticas globais e seus efeitos sobre a biodiversidade:

caracterização do clima atual e definição das alterações climáticas para o território brasileiro ao longo do século XXI. Brasília: MMA, 2007.

MARKHAM, B.L.; BARKER, L. L. Thematic mapper bandpass solar exoatmospherical irradiances.

International Journal of Remote Sensing, v.8, n.3, p.517-523, 1987.

https://doi.org/10.1080/01431168708948658 
NEGASH, S.G. Spatial assessment of NDVI as an indicator of desertification in Ethiopia using remote sensing and GIS. Master (Thesis in Geographicallnformation Science), 2016.

NOVO, E.M.L. Sensoriamento remoto: princípios e aplicações. São Paulo: Blucher,2010.

NULL,J. EI Ninõ winter precipitation and temperature climatology.2017. Disponível em: http://ggweather.com/enso2016/us elnino.html. Acesso em: 20 jan. 2017.

OLIVEIRA, J.B; JACOBINE, P.K.T; CAMARGO, M.N. Classes Gerais de solos do Brasil: guia auxiliar para seu reconhecimento. 2 ed. Jaboticabal: FUNEP, 1992.

OLIVEIRA, D.A.; ROSA, R. Temperatura de superfície obtida com técnicas de geoprocessamento. In: SIMPÓSIO BRASILEIRO DE SENSORIAMENTO REMOTO - SBSR,16., 2013. [Anais...]. Foz do Iguaçu, PR, Brasil, 13 a 18 de abril de 2013, INPE.

OLIVEIRA, T.H.; GALVÍNCIO, J.D. Caracterização ambiental da bacia hidrográfica do rio Moxotó-PE usando sensoriamento remoto termal. Revista Brasileira de Geografia Física, v. 1, n. 2, p. 30-49, 2009. https://doi.org/10.26848/rbgf.v1i2.232620

PERNAMBUCO (ESTADO). Secretaria de Meio Ambiente e Sustentabilidade Ambiental- SEMAS. Plano Estadual de mudanças climáticas. 2011.

PONZONI, F.J.; SHIMABUKURO, Y.E. Sensoriamento remoto aplicado ao estudo da vegetação. 1.ed. S. J. dos Campos: Parêntese. v.1, 2007. 135 p.

PRADO, D. E. As caatingas da América do Sul. Ecologia e conservação da Caatinga, v. 2, p. 3-74, 2003.

SA, I.B.; RICHÉ, G. R.; FOTIUS, G.A. As paisagens e o processo de degradação do semi-árido nordestino. Embrapa Semiárido - Capítulo em livro científico (ALICE), 2003.

TASUMI, M. Progress in operational estimation of regional evapotranspiration using satellite imagery. PhD thesis. Idaho: University of Idaho, 2003, 378p.

TOMLINSON, C. J.; CHAPMAN, L.; THORNES, J. E.; Baker, C. Remote sensing land surface temperature for meteorology and climatology: a review. Meteorological Applications, v18, n.3, p. 296306, 2011. https://doi.org/10.1002/met.287

WENG, Q.; LU, D.; SCHUBRING, J. Estimation of land surface temperature-vegetation abundance relationship for urban heat island studies. Remote sensing of Environment, v. 89, n. 4, p. 467-483, 2004.https://doi.org/10.1016/j.rse.2003.11.005

USGS -United States Geological Survey. Using the USGS Landsat 8 Product. Disponível em: https://landsat.usgs.gov/Landsat8 Using_Product.php. Acesso em: 20 nov 2019.

VELLOSO, A.L.; SAMPAIO, E. V. S. B.; PAREYN, Frans G. C. ECORREGIÕES: Propostas para o Bioma Caatinga. Associação Plantas do Nordeste; Instituto de Conservação Ambiental The Nature Conservancy do Brasil. Recife/PE, 2002. 